\title{
Ventilation/carbon dioxide production ratio in early exercise predicts poor functional capacity in congestive heart failure
}

\author{
R V Milani, M R Mehra, T K Reddy, C J Lavie, H O Ventura
}

\begin{abstract}
Objectives-To evaluate whether changes in the ventilation/carbon dioxide production ratio during early exercise could reliably serve as a surrogate marker for maximal oxygen consumption in heart failure patients. Maximal oxygen consumption is an important determinant of the severity of congestive heart failure with values $>14 \mathrm{ml} / \mathrm{kg} / \mathrm{min}$ confering a good 2-year survival. However, many patients undergoing cardiopulmonary exercise testing cannot exercise maximally because of other functional limitations.
\end{abstract}

Methods-Ventilation/carbon dioxide production ratio was assessed at rest, anaerobic threshold, and peak exercise in 75 patients with chronic heart failure and in 12 healthy controls. Patients were divided into two groups on the basis of heart failure severity as judged by maximal oxygen consumption.

Results-Patients with mild-moderate heart failure had a $20 \%$ reduction in the ventilation/carbon dioxide production ratio at anaerobic threshold similar to that in healthy controls. Patients with severe heart failure failed to reduce this ratio at anaerobic threshold. Furthermore, a reduction in the ventilation/carbon dioxide production ratio in early exercise of less than $10 \%$ predicted a maximal oxygen consumption of $<14$ $\mathrm{m} / \mathrm{kg} / \mathrm{min}$ with a positive predictive value of $96 \%$ and a negative predictive value of $88 \%$.

Conclusions-A reduction of the ventilation/carbon dioxide production ratio of less then $10 \%$ with early exercise reliably predicts poor functional capacity in congestive heart failure. Changes in this ratio during early exercise may be used as a surrogate for maximal oxygen consumption in patients who cannot exercise maximally.

(Heart 1996;76:393-396)

Keywords: heart failure; oxygen uptake; exercise tolerance; cabon dioxide output

Cardiopulmonary exercise testing is a useful clinical tool in assessing the severity of functional impairment in patients with congestive heart failure. ${ }^{1}$ Maximal oxygen uptake during exercise $\left(\mathrm{VO}_{2 \max }\right)$ not only allows accurate evaluation of exercise capacity, but has also been shown to be a strong predictor of clinical outcome in patients with heart failure. ${ }^{2}$ Thus a $\mathrm{VO}_{2 \max } \leqslant 14 \mathrm{ml} / \mathrm{kg} / \mathrm{min}$ is associated with a decreased one year survival of $47 \%$ and a two year survival of $32 \% .{ }^{3}$ This important clinical observation has been widely applied in risk stratification of patients with moderate to severe heart failure and is currently used to assess the urgency of considering cardiac transplantation in those patients in whom clinical variables alone are insufficient in predicting prognosis. However, many patients are unable to achieve $\mathrm{VO}_{2 \max }$ because of severe peripheral muscular deconditioning, low threshold angina, or peripheral vascular disease. Likewise, maximal exercise testing in some patients may lead to severe myocardial ischaemia or malignant dysrhythmias. In such patients a surrogate marker of $\mathrm{VO}_{2 \max }$ that can be analysed at low thresholds of exercise would be desirable. Carbon dioxide output is closely linked to the regulation of ventilatory function of the lungs during exercise. Minute ventilation and carbon dioxide output are predictably related by the alveolar gas equation, and this relation remains coupled throughout exercise in normal individuals. ${ }^{4}$ Conversely, although this relation has been reported to become uncoupled in patients with advanced heart failure, ${ }^{5}$ little is known about the clinical utility of changes in the ventilation/carbon dioxide production ratio in early exercise as it relates to the severity of advanced heart failure. The purpose of our investigation was twofold: first, to establish the clinical utility of measuring the ventilation/carbon dioxide production ratio in early exercise to see whether this variable could serve as a surrogate marker for $\mathrm{VO}_{2 \max }$. Second, to stratify patients with heart failure into high and low risk groups based on the ability of the ventilation/carbon dioxide production ratio to predict maximal aerobic capacity.

\section{Patients and methods}

\section{PATIENTS}

Seventy five consecutive patients with New York Heart Association (NYHA) class II-III heart failure, who were referred for cardiopulmonary exercise testing as part of a heart transplantation evaluation, were prospectively enrolled in the study. The study was approved by the hospital's institutional review committee and all patients gave informed consent. The cause of heart failure was ischaemic heart disease in 49 patients and dilated cardiomy- 
opathy in 26 , and all patients had been in heart failure for more than six months. All patients were on stable doses of their medications and had had no exacerbation of symptoms or need for intravenous inotropic support for at least four weeks before assessment. Patients were excluded if they exhibited severe peripheral vascular disease, significant muscular deconditioning, low threshold angina, or had orthopaedic limitations preventing them from maximal exercise testing. The average age of the 16 females and 59 males was 51 (11) years (range 22-70 years). A control group of 12 healthy non-smoking, age matched subjects also underwent cardiopulmonary exercise testing. The average age of the 11 males and 1 female was 51 (15) years (range 33-73). These subjects were free of any known cardiopulmonary disease. A third group of eleven patients with NYHA class III-IV heart failure who showed exercise limitations because of significant muscular deconditioning or peripheral vascular disease completed cardiopulmonary exercise testing. These patients were also on stable doses of their medications and had had no exacerbation of symptoms or need for intravenous inotropic support for at least four weeks before assessment. The average age of the nine males and two females was 54 (12) years (range 37-71).

\section{CARDIOPULMONARY EXERCISE TESTING}

All patients and healthy controls were exercised maximally on a treadmill using an individually tailored ramping treadmill protocol, designed to give a test lasting 8-12 minutes. ${ }^{6}$ Patients were encouraged to exercise until symptoms were intolerable. Breath to breath gas analysis was performed on-line using a MedGraphics CPX/D metabolic cart. Incremental data including minute ventilation, oxygen consumption, and carbon dioxide production were collected every 15 seconds. From these data, maximal oxygen consump-

Table 1 Baseline demographic and clinical characteristics of heart failure patients in group $1\left(\mathrm{VO}_{2 \max }>14 \mathrm{ml} / \mathrm{kg} / \mathrm{min}\right)$ and group $2\left(\mathrm{VO}_{2 \max } \leqslant 14 \mathrm{ml} / \mathrm{kg} / \mathrm{min}\right)$ and in healthy control subjects (mean (SD))

\begin{tabular}{llll}
\hline Characteristic & $\begin{array}{l}\text { Controls } \\
(n=12)\end{array}$ & $\begin{array}{l}\text { Group 1 } \\
(n=43)\end{array}$ & $\begin{array}{l}\text { Group 2 } \\
(n=32)\end{array}$ \\
\hline Age $(\mathrm{y})$ & $51(15)$ & $51(11)$ & $51(11)$ \\
M/F & $11 / 1$ & $36 / 7$ & $23 / 9$ \\
Weight $(\mathrm{kg})$ & $88 \cdot 9(18 \cdot 0)$ & $83.5(19 \cdot 7)$ & $89 \cdot 3(22.4)$ \\
Body mass index $\left(\mathrm{kg} / \mathrm{m}^{2}\right)$ & $30 \cdot 3(5 \cdot 8)$ & $27 \cdot 6(5 \cdot 7)$ & $30 \cdot 0(5 \cdot 3)$ \\
NYHA class & - & $2 \cdot 7(0 \cdot 5)$ & $2 \cdot 8(0 \cdot 4)$ \\
Ejection fraction & $0.60(0 \cdot 06)$ & $0 \cdot 20(0 \cdot 07)$ & $0 \cdot 21(0.07)$ \\
\hline
\end{tabular}

$\mathrm{VO}_{2 \max }$, maximal oxygen uptake; NYHA, New York Heart Association.

Table 2 Metabolic variables during exercise in heart failure patients in group $1\left(\mathrm{VO}_{2 \max }\right.$ $>14 \mathrm{ml} / \mathrm{kg} / \mathrm{min})$ and group $2\left(\mathrm{VO}_{2 \max } \leqslant 14 \mathrm{ml} / \mathrm{kg} / \mathrm{min}\right)$ and in healthy control subjects (mean (SD))

\begin{tabular}{|c|c|c|c|}
\hline Variable & $\begin{array}{l}\text { Controls } \\
(n=12)\end{array}$ & $\begin{array}{l}\text { Group 1 } \\
(n=43)\end{array}$ & $\begin{array}{l}\text { Group } 2 \\
(n=32)\end{array}$ \\
\hline $\begin{array}{l}\mathrm{V}_{\mathrm{E}} / \mathrm{VCO}_{2} \text { rest } \\
\mathrm{V}_{\mathrm{E}} / \mathrm{VCO}_{2} \mathrm{AT} \\
\mathrm{V}_{\mathrm{E}} / \mathrm{NCO}_{2} \text { peak } \\
\Delta \mathrm{V}_{\mathrm{E}} / \mathrm{VCO}_{2} \text { rest to AT }(\%) \\
\mathrm{VO}_{2} \mathrm{AT}(\mathrm{ml} / \mathrm{kg} / \mathrm{min}) \\
\mathrm{AT}_{\text {time }} / \mathrm{total} \text { exercise time }(\%) \\
\mathrm{VO}_{2 \max }(\mathrm{ml} / \mathrm{kg} / \mathrm{min})\end{array}$ & $\begin{array}{r}36 \cdot 4(4 \cdot 0) \\
29 \cdot 1(2 \cdot 6) \\
31 \cdot 2(4 \cdot 8) \\
-20^{\star} \\
19 \cdot 6(6 \cdot 3) \\
51 \\
29 \cdot 7(7 \cdot 9)\end{array}$ & $\begin{array}{l}42 \cdot 2(7 \cdot 0) \\
33 \cdot 7(5 \cdot 1) \\
35 \cdot 1(5 \cdot 3) \\
-20^{\star} \\
13 \cdot 1(2 \cdot 3) \\
58 \\
18 \cdot 5(2 \cdot 7)\end{array}$ & $\begin{array}{l}42 \cdot 1(7 \cdot 9) \\
40 \cdot 1(7 \cdot 3) \\
40 \cdot 8(8 \cdot 2) \\
-5 \\
9 \cdot 1(2 \cdot 1) \\
58 \\
11 \cdot 7(1 \cdot 8)\end{array}$ \\
\hline
\end{tabular}

tion, anaerobic threshold, and respiratory exchange ratio were calculated as previously described. ${ }^{7} \mathrm{VO}_{2 \max }$ was determined after failure to increase oxygen uptake despite increasing workload. The ventilation/carbon dioxide production ratio was averaged and plotted against time at baseline, anaerobic threshold, and at maximal oxygen consumption. Heart failure patients were divided in to two groups, based on $\mathrm{VO}_{2 \max }$ attained, with group 1 (mild to moderate) having a $V_{2} O_{\max }>14 \mathrm{ml} / \mathrm{kg} / \mathrm{min}$ and group 2 (severe) achieving a $\mathrm{VO}_{2 \max } \leqslant 14$ $\mathrm{ml} / \mathrm{kg} / \mathrm{min}$.

\section{ECHOCARDIOGRAPHY}

All subjects underwent standard cross sectional echocardiography within three months of evaluation. Ejection fraction was visually estimated by two experienced echocardiographers in our non-invasive laboratories and reported as the average of the two..$^{89}$ Both observers were independently blinded to the review of all data.

\section{STATISTICAL ANALYSIS}

Between group analysis was performed with Student's $t$ test and by chi square analysis. Linear regression using the least squares method was used. $P$ values $\leqslant 0.05$ were taken to be significant. Data are expressed as mean (SD).

\section{Results}

\section{PATIENT CHARACTERISTICS}

Baseline demographic and clinical characteristics of heart failure patients and healthy controls are outlined in table 1 . Of the cohort of 75 heart failure patients, $43(57 \%)$ were classified as having mild to moderate heart failure (group 1), achieving a $V O_{\text {max }}>14 \mathrm{ml} / \mathrm{kg} / \mathrm{min}$ (mean $18.5(2.7)$, range 14.1 to $27.9 \mathrm{ml} / \mathrm{kg}$ / $\mathrm{min})$, and $32(43 \%)$ were classified as having severe heart failure (group 2) with a $\mathrm{VO}_{2 \max }$ $\leqslant 14 \mathrm{ml} / \mathrm{kg} / \mathrm{min}$ (mean $=11.7(1.8)$, range 7.6 to $14.0 \mathrm{ml} / \mathrm{kg} / \mathrm{min}$ ). There were no differences in age, gender, New York Heart Association classification, ejection fraction, or cardiac medications between groups 1 and 2 .

\section{VENTILATION/CARBON DIOXIDE PRODUCTION} RATIO

Table 2 shows the calculated ventilation/ carbon dioxide production ratio at each of the three exercise time points. At rest, there was no difference in the mean ratio for patients in groups 1 and $2(42 \cdot 2(7 \cdot 0) v 42 \cdot 1(7 \cdot 9) ; \mathrm{P}=$ NS), although these were significantly higher than the ratio of $36 \cdot 4(4 \cdot 0)$ in healthy controls $(\mathrm{P}<0.05$ compared with both groups 1 and 2). Anaerobic threshold was achieved at $51 \%$ of the total exercise time, and the mean ventilation/carbon dioxide production ratio dropped $20 \%$ to $29.1(2.6)(P<0.0001)$ in the healthy controls. In group 1 , anaerobic threshold occurred at $58 \%$ of the total exercise time, and the ratio dropped $20 \%$ to 33.7 (5.10 $(\mathrm{P}<0.0001)$. However, in group 2 , the ratio fell insignificantly by $5 \%$ to $40 \cdot 1(7 \cdot 3),(P=$ NS) despite the anaerobic threshold occurring 


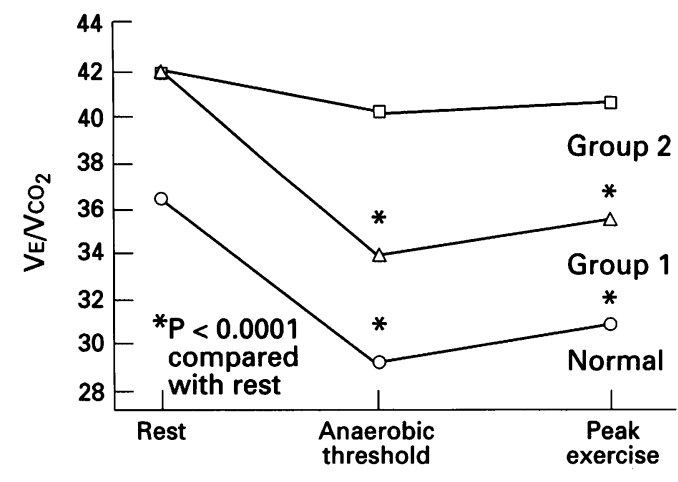

Figure 1 Changes in ventilation/carbon dioxide production ratio $\left(\mathrm{V}_{\mathrm{E}} / \mathrm{VCO}_{2}\right)$ at baseline, anaerobic threshold, and peak exercise in healthy controls $(n=12)$, patients with mild-moderate heart failure (group 1 ( $n=$ 43): $\left.V O_{2 \max }>14 \mathrm{ml} / \mathrm{kg} / \mathrm{min}\right)$, and in patients with severe heart failure (group $2(n=32): V O_{2 \max } \leqslant 14$ ml/kg/min).

at $58 \%$ of total exercise. Although, there was no difference in the ventilation/carbon dioxide production ratio between heart failure groups at baseline, this relation became widely disparate at both anaerobic threshold $(33 \cdot 7(5 \cdot 1) v$ $40 \cdot 1(7 \cdot 3), \mathrm{P}<0.0001)$ and at $\mathrm{VO}_{2 \max }(35 \cdot 1$ $(5 \cdot 3) v 40.8(8 \cdot 2), \mathrm{P}<0.001)$ in groups 1 and 2 respectively (fig 1 ).

\section{VENTILATION/CARBON DIOXIDE PRODUCTION RATIO AND PREDICTION OF $\mathrm{VO}_{2 \max }$}

The relation between change in the ventilation/carbon dioxide production ratio during early exercise and maximal oxygen consumption was relatively linear in the heart failure patients ( $r=0.65 ; p<0.0001$ ) (fig 2). Twenty six $(81 \%)$ of the 32 group 2 patients demonstrated a reduction of the ventilation/carbon dioxide production ratio of less than $10 \%$, whereas, $42(98 \%)$ of the 43 group 1 patients had a ratio reduction of greater than $10 \%$.

\section{RESULTS IN PATIENTS WITH EXERCISE LIMITATIONS}

To test the validity of using the ventilation/

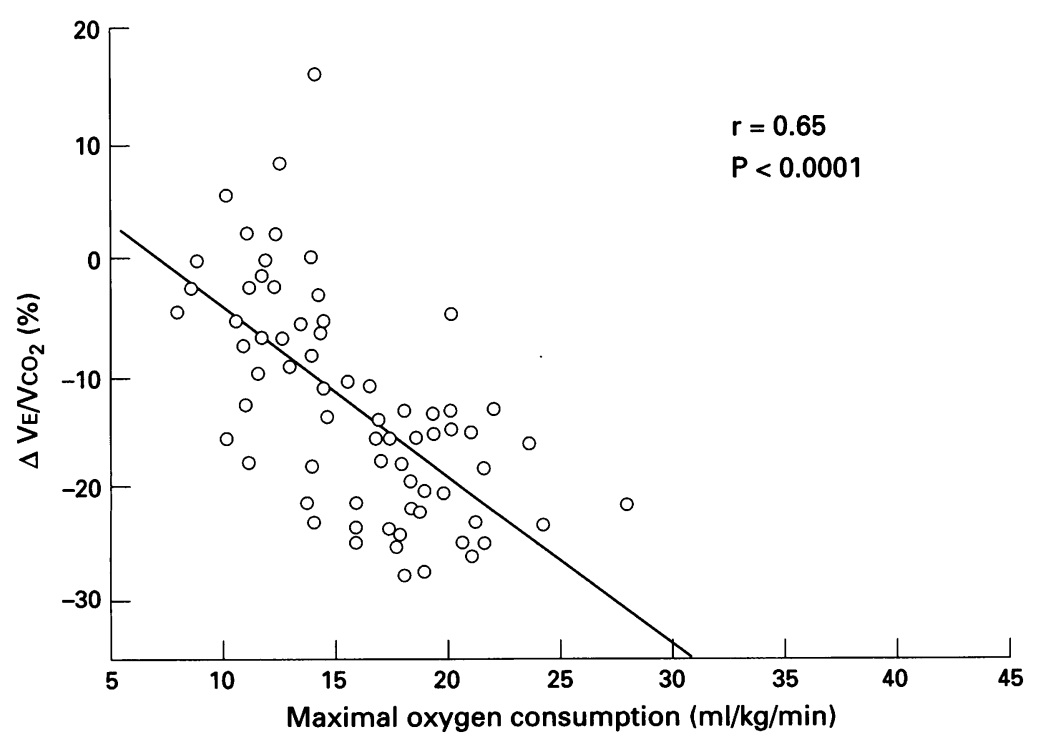

Figure 2 Relation between the reduction in ventilation/carbon dioxide production ratio $\left(V_{E} / \mathrm{CO}_{2}\right)$ with early exercise and the severity of heart failure as determined by maximal oxygen uptake $\left(V \mathrm{O}_{2 \max }\right)$ in 75 heart failure patients. carbon dioxide production ratio during early exercise in heart failure patients with exercise limitations, 11 patients with these limitations were assessed. All patients in this group achieved anaerobic threshold; however, the mean total exercise time was significantly impaired (5.9 $(0.7)$ minutes). The mean ventilation/carbon dioxide production ratio fell by $16(9) \%$ for the group. Although the mean peak $\mathrm{VO}_{2}$ was $11 \cdot 1(2 \cdot 6) \mathrm{ml} / \mathrm{kg} / \mathrm{min}$ for the group, seven patients achieved a reduction in the ventilation/carbon dioxide production ratio of greater than $10 \%$ (mean $=21(5 \%)$ ).

\section{Discussion}

The results of our study demonstrate that changes in the ventilation/carbon dioxide production ratio with early exercise predict severity of congestive heart failure as judged by maximal oxygen consumption. Furthermore, lack of a $10 \%$ decrease in the ventilation/carbon dioxide production ratio from rest to anaerobic threshold identifies heart failure patients with severely impaired aerobic capacity $\left(\mathrm{VO}_{2 \max } \leqslant 14 \mathrm{ml} / \mathrm{kg} / \mathrm{min}\right)$ with a sensitivity of $81 \%$ and specificity of $98 \%$. Thus, early measurement of ventilation/carbon dioxide production ratio reliably stratifies patients with heart failure by predicting high and low maximum oxygen consumption, a finding of particular importance in patients who fail to achieve peak aerobic capacity. The relation between ventilation and carbon dioxide production during exercise varies with the arterial carbon dioxide and the dead space fraction. ${ }^{4}$ Normal subjects (as in our healthy controls) demonstrate a decrease in the ventilation/carbon dioxide production ratio at the onset of exercise and thereafter a small increase in the ratio towards the end of peak exercise. While the former may reflect an increase in arterial carbon dioxide or a decrease in the dead space fraction, the latter may result from either an increase in the dead space fraction or another drive to ventilation resulting in a decrease in arterial carbon dioxide. ${ }^{510}$ The response of the ventilation/carbon dioxide production ratio to exercise in patients with heart failure, however, has been found to be highly variable. ${ }^{11-13} \mathrm{~A}$ previous study by Clark et al described three distinct patterns of ventilation/carbon dioxide production ratio response to exercise in a group of 29 patients with varying degrees of heart failure. ${ }^{5}$ While their study concluded that these patterns correlated with heart failure severity, their measure of severity was exercise time alone, and not maximal oxygen consumption, a more clinically relevant measure of prognosis. Furthermore, the assessment of an adequate ventilation/carbon dioxide production ratio response pattern was based on the prerequisite of completion of maximal exercise. Our findings lend support to these prior observations and further demonstrate that assessment of this ratio not only risk stratifies patients with heart failure based on the clinically meaningful variable of $\mathrm{VO}_{2 \max }$, but also suggest that this can be reliably achieved even at submaximal exercise. While attain- 
ment of $\mathrm{VO}_{2 \max }$ is clearly desirable for assessment of prognosis in heart failure, several limitations are often present that preclude its successful determination. These limitations include low threshold angina, peripheral vascular disease, orthopaedic impairments, and skeletal muscle atrophy. Although, the prevalence of each of these conditions varies in patients with heart failure, skeletal muscle atrophy seems to be relatively common and can significantly impair exercise capacity. Indeed, in a study evaluating the prevalence of skeletal muscle atrophy in heart failure, a significant diminution in muscle mass was found in $68 \%$ of 62 patients evaluated, and this directly correlated with peak exercise oxygen consumption. ${ }^{14}$ Furthermore, in a study of 57 heart failure patients, Drexler et al found a significant reduction in the mitochondrial density of skeletal muscle, which correlated to the duration of heart failure as well as the maximal oxygen consumption. ${ }^{15}$ These data reveal that the reduced density and oxidative capacity of skeletal muscle in heart failure is a prevalent finding, especially in long standing heart failure, and would significantly reduce exercise capacity and the ability to attain $\mathrm{VO}_{2 \max }$. Our study enables the clinician to evaluate indirectly peak aerobic capacity by early changes in the ventilation/carbon dioxide production ratio response and might allow prognostic assessment based on peak aerobic capacity in patients who fail to achieve $\mathrm{VO}_{2 \max }$. Indeed, this investigation demonstrates that a less than $10 \%$ decrease in the ventilation/carbon dioxide production ratio from rest to anaerobic threshold correctly identifies heart failure patients with severely impaired aerobic capacity $\left(\mathrm{VO}_{2 \max } \leqslant 14 \mathrm{ml} / \mathrm{kg} / \mathrm{min}\right.$ ) with a positive predictive value of $96 \%$ and a negative predictive value of $88 \%$. In conclusion, changes in the ventilation/carbon dioxide production ratio with early exercise predict severity of congestive heart failure as judged by maximal oxygen consumption. These findings might be useful to provide prognostic risk stratification of patients with chronic heart failure, a finding of particular relevance in the many patients who cannot achieve maximal aerobic capacity.

We thank Barbara Hand who assisted with data collection for this study.

1 Weber KT, Janicki JS. Cardiopulmonary exercise testing for evaluation of chronic cardiac failure. $A m \mathcal{F}$ Cardio 1985;55:22A-31A.

2 Cohn JN, Archibald DG, Francis GS, et al. Veteran administration cooperative study on vasodilator therapy
of heart failure: influence of prerandomization variables of heart failure: influence of prerandomization variables on the reduction of mortality by treatment with hydralazin

3 Manicni DM, Eisen H, Kussmaul W, Mull R, Edmund $\mathrm{LH} \mathrm{Jr}$, Wilson JR. Value of peak exercise oxygen consumption for optimal timing of cardiac transplantation in ambulatory patients with heart failure. Circulation 1991; 83:778-86.

4 Whipp BJ, Ward SA, Wasserman $\mathrm{K}$. Ventilatory responses to exercise and their control in man. Am Rev Resp Dis 1984;129:S17-20.

5 Clark AL, Poole-Wilson PA, Coats AJS. Relation between ventilation and carbon dioxide production in patients with congestive heart failure. $\mathcal{f}$ Am Coll Cardiol 1992;20: with congesti

6 Myers J, Buchanan N, Walsh D, Kraemer M, McAuley P,. Hamilton-Wessler M, Froelicher V. Comparison of the ramp versus standard exercise protocols. F $\mathrm{Am}$ Coll Cardiol 1991;17:1334-42.

7 Wasserman K. New concepts in assessing cardiovascula function. Circulation 1988;78:1060-71.

8 Rich S, Shiekh A, Gallastegui J, Kondos GT, Mason T, Lam W. Determination of left ventricular ejection fraction by visual estimation during real-time two-dimensional echocardiography. Am Heart $₹$ 1982;104:603-6.

9 Amico AF, Lichtenberg GS, Reisner SA, Stone CK, Schwartz RG, Meltzer RS. Superiority of visual versus cchwartz RG, Meltzer RS. Superiority of visual versu computerized echocardiographic estimation of radionuclide left ventricular

10 Rajfer SI, Nemanich JW, Shurman AJ, Rossen JD. Metabolic responses to exercise in patients with heart failure. Circulation 1987;76:VI46-53

11 Weber KT, Kinasewitz GT, Janicki JS, Fishman AP. Oxygen utilization and ventilation in patients with chronic cardiac failure. Circulation 1982;65:1213-23.

12 Buller NP, Poole-Wilson PA. Mechanism of the increased ventilatory response to exercise in patients with chronic heart failure. Br Heart $f 1990 ; 63: 281-3$.

13 Sullivan MJ, Higginbotham MB, Cobb FR. Increased exercise ventilation in patients with chronic heart failure: intact ventilatory control despite hemodynamic and pulintact ventilatory control despite hemodynamic and

14 Mancini DM, Walter G, Reichek N, et al. Contribution of skeletal muscle atrophy to exercise intolerance and altered muscle metabolism in heart failure. Circulation 1992;85:1364-73.

15 Drexler H, Riede U, Münzel T, König H, Funke E, Just H. Alterations of skeletal muscle in chronic heart failure. Circulation 1992;85:1751-9. 